\title{
Managing strategic improvement programs: the XPS program management framework
}

Torbjørn Netland

Norwegian University of Science and Technology

\begin{abstract}
Multinational corporations are introducing holistic company-specific production systems (XPSs) in order to improve the productivity of their global manufacturing networks. XPSs are multi-plant improvement programs that are coordinated from the corporate headquarters and implemented in all subsidiaries of the firm. However, research and practice show that the implementation of process improvement programs is a challenging task that often ends up unsuccessful despite good intentions and substantial resource investments.
\end{abstract}

In this paper, I investigate how program management theory can help provide deployment guidelines for successful XPS implementation in global firms. I am proposing an XPS program management framework, which has been developed through merging program management theory with descriptions of real-life XPSs. It is suggested that the structured approach found in project-based program management literature can be partly adapted to strategic programs such as the XPS.

This paper contributes to program management theory by enhancing our understanding of how strategic programs, such as XPSs, differ from other more project-based types of programs. Secondly, it contributes to the process improvement literature with practical management guidelines for XPS deployment adapted from program management theory.

Keywords: program management, process improvement, XPS, lean production, global operations, strategic programs

\section{Introduction}

Multinational companies are implementing an increasing number of improvement programs; they spend more money, more often and on bigger programs (Williams \& Parr 2004). A shared aim of all the programs is change in one form or another. A specific type of program that has received a lot of attention and spending among multinational manufacturing companies in the past decade is the company-specific production system (XPS ${ }^{\mathrm{i}}$ ) (Netland 2012). An XPS is a process improvement program that corporations develop and deploy in order to improve the competitiveness of their worldwide manufacturing operations. The XPS is customised for the corporation and based on a mix of proven improvement philosophies such as lean, Six Sigma, total quality management, and world class manufacturing. XPSs are often company-specific variants of the Toyota Production System, tailored to the needs and characteristics of the corporation (Netland \& Aspelund 2013).

Program management is a popular approach for bringing about change in corporations. According to Pellegrinelli et al. (2007: 41), 'the widespread use of program management has outpaced our ability to grasp and codify a complex and subtle phenomenon'. For a number of reasons, program management is often unsuccessful (Lycett et al. 2004; Williams \& Parr 2004). This is also true for programs targeting process improvement (Bateman \& David 2002; Schonberger 2007). Therefore, in order to aid managers at all levels in the 
multinational corporation in their efforts to successfully implement and sustain their XPSs, there is a need to elucidate XPS program management. This paper brings the program management perspective to the XPS literature by investigating how program management theory can help provide deployment guidelines for a very specific and popular type of corporate program: the XPS.

In the nascent program management literature (Vereecke et al. 2003; Milosevic et al. 2007), there are very few contributions that deal with these types of strategic multi-plant improvement programs. The majority of empirical studies in program management theory stem from the project management perspective. Vereecke et al. (2003), for example, discuss e-business development and organisational redesign in global service firms. Williams and Parr (2004) explain how program management theory can help organisations carry out megaprojects such as improving traffic congestion in London, launching a new multi-company integrative webpage, global re-organisation, etc. These are all important programs for the respective organisations, but they differ fundamentally in a number of ways from the XPSas will be further elaborated upon in this paper.

\section{Literature review of program management frameworks}

Program management has become an acknowledged discipline over the last decade. It has its roots in project-based industries such as defence, aerospace, financial services, software development and telecommunications (Pellegrinelli 2008) ${ }^{\text {ii }}$. Every organisation is engaged in program management in one way or another (Reiss 1996), but program management as an organisational discipline is still less widespread in traditional manufacturing industries. Despite an increasing number of handbooks and guidelines, there is still only limited guidance for managers who undertake large and complex programs (Pellegrinelli 2008). This belies the substantial importance, resource intensity and risk connected to program management in practice:

\footnotetext{
Programs are often the way organisations manage their key strategic investments. It is critical, if maximum value is to be reaped from these investments, that organisations, develop program management capabilities and invest in the appropriate infrastructure to support delivery of their programs (Williams \& Parr 2004: 42).
}

There are two strands of program management literature (Pellegrinelli et al. 2007): project management literature typically describes program management as the management of mega-projects or a portfolio of projects (Ferns 1991; Reiss 1996; Gray 1997; Springer 2001; Vereecke et al. 2003; Milosevic et al. 2007; OGC 2007, 2011), while strategic management literature typically views program management as an abstract vehicle for bringing about organisational change (Pellegrinelli 1997; Thiry 2002). Where project-type programs are described by linear project plans, strategic programs take the form of frameworks and structures (Pellegrinelli et al. 2007).

One of the sharpest conflicts between these two strands is the definition of a program as infinite by the strategic management view (Pellegrinelli 1997) as opposed to finite by the project management view (Milosevic et al. 2007). Reiss (1996: 7) simply declares that 'projects end, programs don't'. Williams and Parr (2004: 44) maintain that 'programs can be on-going and do not end until they are judged completed or not longer relevant'. In contrast, Milosevic et al. (2007: 8) define program management as 'the coordinated management of interdependent projects over a finite period of time to achieve a set of business goals'. The latter standpoint is supported by Springer (2001: 374), who defines a program as 'an activity 
that has a defined starting point, clearly defined objective, a definite ending point, and requires resources to execute'. However, as I will elaborate later on, a dispute concerning finiteness versus infiniteness is not fruitful for the advancement of our understanding of strategic programs.

I now go on to review the available management frameworks from these two perspectives:

- The project-based perspective on program management

- The strategic perspective on program management

Project-based program management frameworks: MSP and EPM

Most program management textbooks are filled with traditional project management techniques and models (Reiss 1996; Springer 2001; Williams \& Parr 2004). Reiss (1996) and Williams and Parr (2004) describe in detail how typical project management techniques and tools can all contribute to better program management in practice ${ }^{\mathrm{iii}}$. Many of these wellknown techniques and standards are of course of great benefit to the XPS manager as well, but it is not at this level of detail that confusion arises between the strategic and the projectbased perspectives. Therefore, this paper focuses on the overall program management.

The UK Office of Government Commerce published Managing Successful Programmes (MSP) (OGC 2007, 2011), which has gained a foothold as a guide for program management in practice (Pellegrinelli 2008). Revisions of the MSP since 2003 have addressed criticism that the MSP advocates a too standardised and bureaucratic project approach to program management, but the text still takes a system approach. Today MSP promises that "program management principles may be applied to any change, whatever the level of its focus or the nature of its outcome, and can provide structure and process to support all types of change' (OGC 2011: 10).

The MSP framework (OGC 2011) is a holistic, structured and detailed account of how to manage programs from the start to the end (Figure 1). It takes a process perspective; a company moves in a 'transformational flow' through the following phases: 'identifying', 'defining', 'establishing', 'managing the tranches', 'reviewing and preparing', and finally 'closing the program'. For each phase, there are nine governance themes that explain what must be done, and seven principles that must be continuously adhered to. 


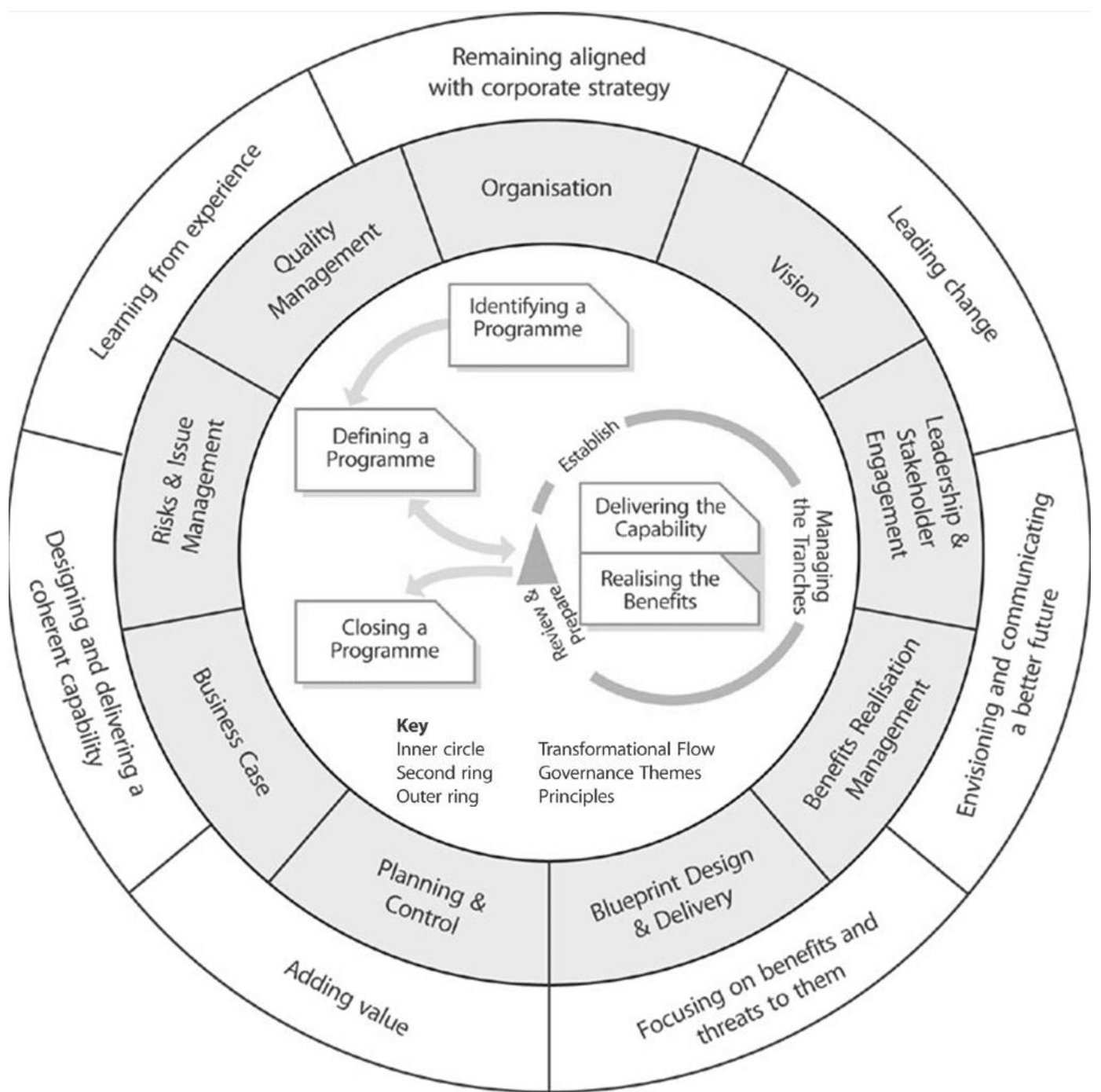

Figure 1: The MSP framework and concepts (OGC 2011: 6, figure 1.1)

Williams and Parr (2004) present a similar Enterprise Program Management (EPM) framework with a detailed overview of the structures, processes and tools needed to succeed at program management (Figure 2). Two pillars - 'program architecture' and 'change architecture' - are central to the EPM framework. Program architecture is 'the establishment of leadership structures, team dynamics, behaviours and support mechanisms that enable the delivery of programs and projects' (Williams \& Parr 2004: 15), and change architecture is about managing the 'people' side of change. 


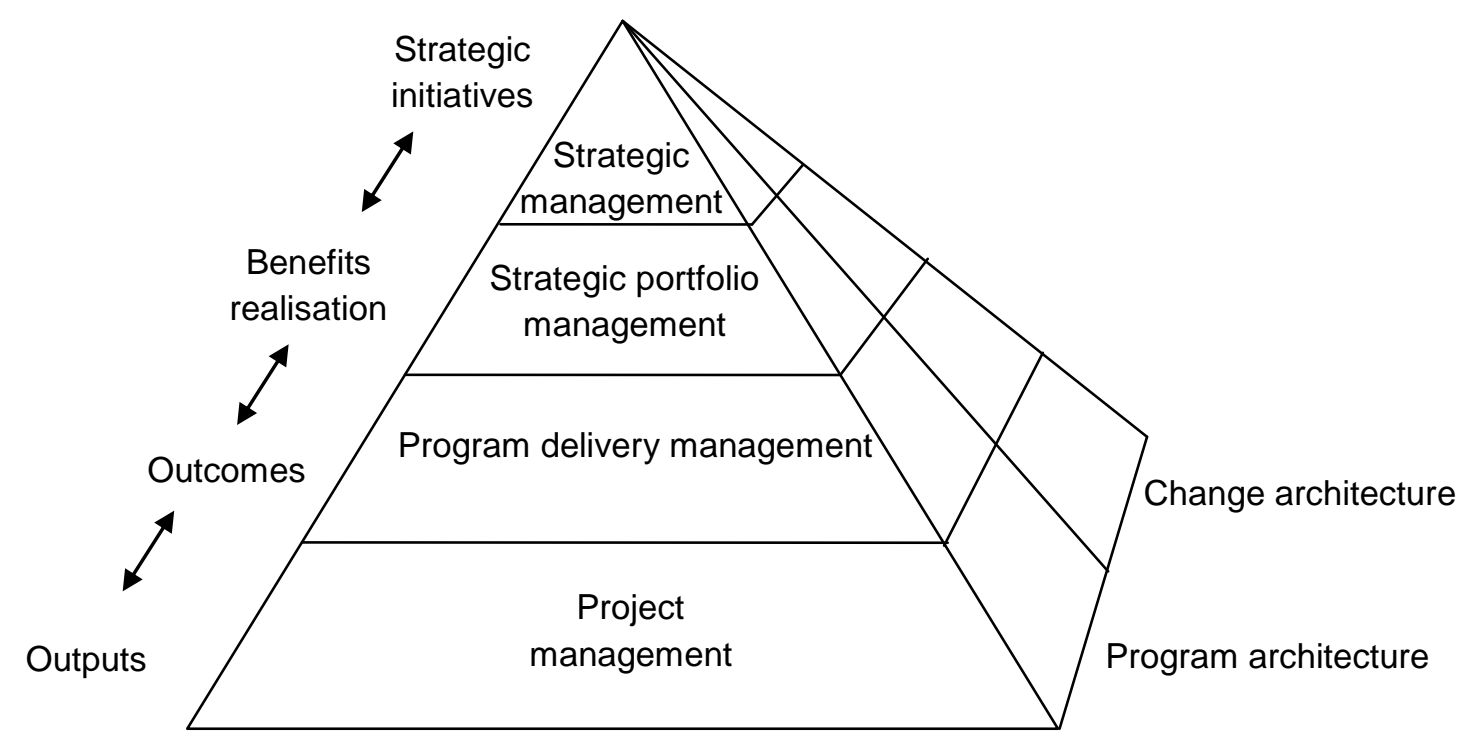

Figure 2: The EPM framework (Williams \& Parr 2004: 12, fig. 2.4)

Clearly, there is a strong similarity between Williams and Parr's (2004) two supporting pillars and the second and outer ring of the MSP framework, as well as between the program delivery module of the EPM framework and the inner circle of the MSP framework. Both frameworks share this tripartition, which I will describe as the purpose (or content), structure and process of the program. The purpose is to deliver a change in content through program management, the structure is the organisational elements put up to enable delivery of the content, and the process is the mechanism that delivers the change.

\section{The strategic perspective on program management}

The one-size-fits-all recipe for program management that has been advocated by the projectbased perspective has been criticised (Vereecke et al. 2003; Lycett et al. 2004; Pellegrinelli et al. 2007). The strategic improvement program perspective is fundamentally different from the mega-implementation projects often referred to by the project-based perspective. Lycett et al. (2004) criticise program management for being handled as a scaled-up version of a project in practice. The MSP framework is based on the classic project management principles of role hierarchy, linear lifecycles, defined activities, structure and control (Lycett et al. 2004; Pellegrinelli et al. 2007). According to Lycett et al. (2004), program management is much more than how it is often treated; mega-projects run the risk of 'excessive hierarchical bureaucracy and control' and 'a focus on an inappropriate level of detail'.

Strategic programs differ from project-based programs in that the former are (Thiry 2002; Pellegrinelli et al. 2007):

- Proceeding

- Emergent

- Dynamic

- People-oriented

Strategic programs are proceeding because they do not have an intended end-point or enddate. The program aims to implement a state of continuous organisational learning and improvement that by definition is never-ending. They are dynamic in that they should continuously adapt to changes in the environment and to changes in the system they aim to change. The program must constantly 'raise the bar' if competitors improve or the company 
itself improves. They are emergent in that they are not neatly defined and completely designed before they start. They are people-oriented because they target deep cultural change that requires all employees to be included in the program.

Vereecke et al. 's (2003) case analysis of six programs concludes that there is less centralisation, less formalisation and less management taking place in practice than is argued for in the project-based program management literature. Pellegrinelli et al. (2007) find that the often suggested guidelines are implemented in many different ways in a multinational corporation. The guidelines are frequently adapted, ignored or manipulated to create a better fit in the subsidiary. In contrast, 'MSP tends to support a tactical, controlling agenda rather than a strategic, empowering agenda' (Pellegrinelli et al. 2007). The strategic perspective maintains that programs are context dependent; they need a fit between their purpose and organisational setting. Thus, different subsidiaries within a multi-national corporation will adapt the same program in different ways.

Lycett et al. (2004) argue that there is a need to bring perspectives of relationship management, power dynamics, and adaption to contingencies into program management theory. Thiry (2002) takes this a step further and recommend to end the performance-oriented paradigm that prevails in contemporary program management. In other words, he argues that 'people issues' should be integrated into the field of program management, through activities such as 'learning, value management, sense making, information sharing, group decision support and shared construction of statements' (Thiry 2002: 222). In the same vein, Pellegrinelli et al. (2007) argue that ambiguity and uncertainty must be accepted as part of a successful improvement program because contingencies matter.

\section{The XPS program}

This section synthesises commonalities among 15 XPSs that the author has previously studied (Netland 2012) ${ }^{\text {iv }}$ and draws on XPS literature where appropriate. The purpose of this section is to describe a stereotypical XPS, which can be used to propose a generic XPS program management framework in the subsequent discussion section. The included XPSs are given in Table 1 and are all implemented by renowned multinational companies. While the Netland (2012) paper only focused on the content of XPSs, this paper takes a more holistic perspective by also including program structure and process.

\section{Table 1: Fifteen XPSs studied to describe a stereotypical XPS}

\begin{tabular}{ll} 
- Alfa Laval Production System & - John Deere Quality and Production \\
- Audi Production System & System \\
- Bosch Production System & - Novo Nordisk's cLean \\
- Elkem Business System & - REC Production System \\
- Formel ZF Production System & - Scania Production System \\
- Haldex Way & - Valeo's 5 axes / Valeo Production \\
- Herman Miller Production System & System \\
- Hydro Aluminium Metal Production System & - Volvo Production System \\
& - Lemförder Production System \\
\hline
\end{tabular}

\section{XPS content}

The content of the stereotypical XPS has been studied and explained in several studies (Honnef et al. 2000; Netland 2012). Both practice and theory establish that XPSs are strongly influenced by lean production and the Toyota Production System (MacDuffie 2000; Clarke 2005; Dombrowski et al. 2009; Westkämper et al. 2009). The XPS content thus comprises 
well-known principles, techniques and tools, which are described in a rich improvement literature.

XPS content is often summarised in an XPS model. Examples are the use of a house for the Toyota Production System, a pyramid for the Volvo Production System, a car in the early versions of the Audi Production System, a staircase for the Hydro Aluminium Metal Production System and so on. A common characteristic of XPSs is that the different systems are adapted to a varying degree to each company's design and language. The XPS represents 'an own-best-way approach to the one-best-way paradigm' (Netland 2012). A key idea is that all subsidiaries within a multinational corporation share the same XPS content, which represents a departure from the traditional hands-off approach to process improvement among subsidiaries.

\section{XPS structure}

Companies establish necessary structures to support the implementation of XPS content, which comprises both organisational and technical elements. An XPS-superstructure is established at the corporation level, while each subsidiary must establish its own support structures for implementation. The organisational superstructure typically consists of an XPS Program Office and a matrix XPS organisation in the line organisation. The XPS Program Office 'owns' the XPS and supports implementation within the organisation. The technical structure usually consists of intranet pages with best practice databases and teaching material.

\section{XPS process}

The XPS process explains how the XPS is implemented in the organisation. It covers the actions that lead to implemented change. This includes a wide variety of organisational mechanisms, such as leadership, managerial commitment and follow-up, resource management, policy deployment, employee training, sending expats to plants, inclusion of the union, assessments of the current state of affairs, establishing awards, socialisation efforts, and so on. This process naturally takes very different forms across corporations and also across subsidiaries within the same corporation.

Many firms develop an XPS audit that works as a guideline for implementation and is performed in all subsidiaries as self-assessments or external assessments. XPS audits motivate the change and helps multinational companies identify best practices in the subsidiaries. Often, these audits measure the degree of implementation of the XPS on a 5point scale from none to full implementation. It is possible to sketch a typical XPS lifecycle that illustrates the typical path over the four implementation phases and the five maturity levels (Figure 3). 


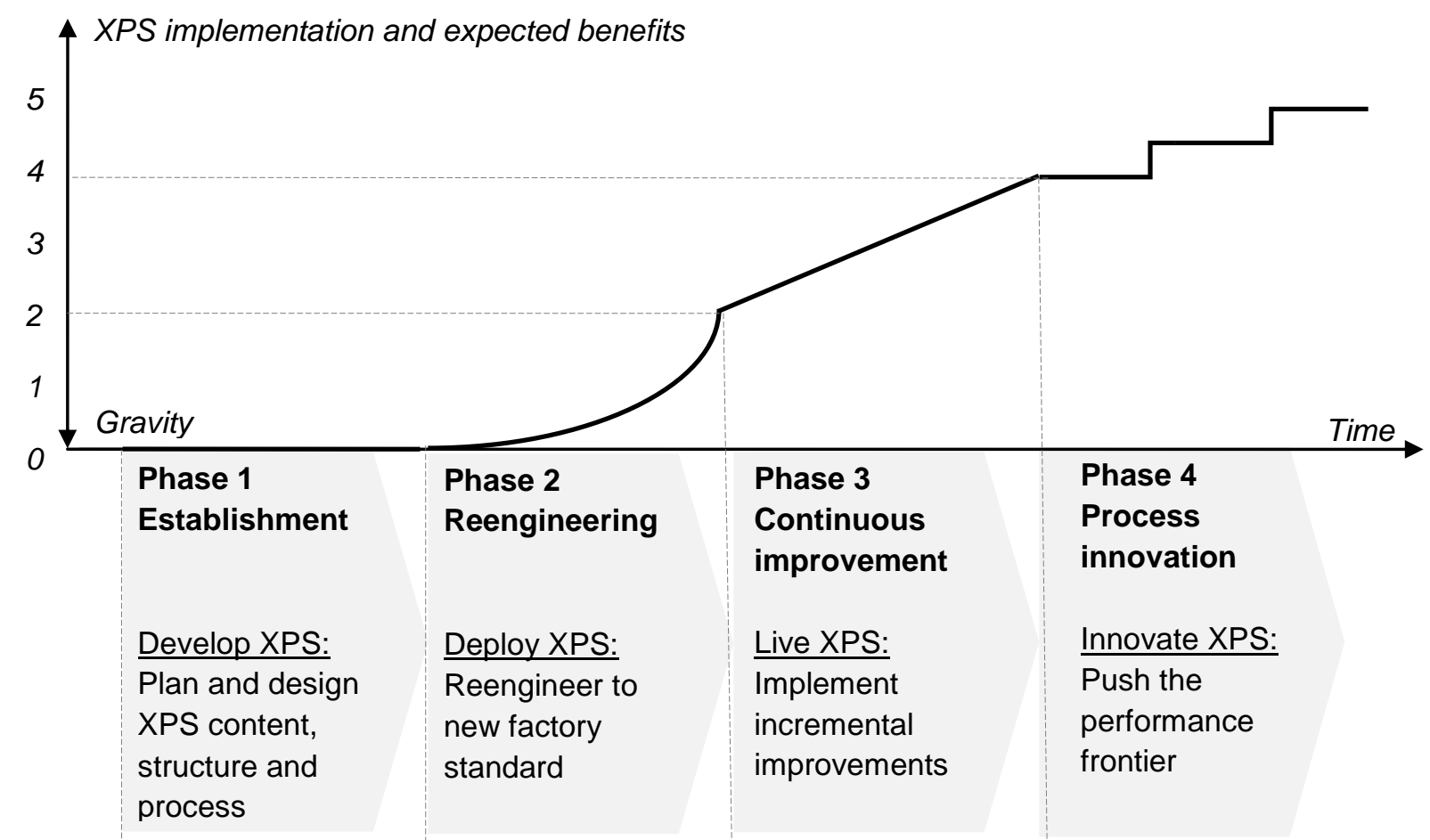

Figure 3: The typical lifecycle of XPS implementation in a subsidiary

In Phase 1, 'Establishment', the XPS program necessarily takes the form of a project. The XPS starts with a top-management decision to develop an XPS for the firm. Traditional project management techniques are needed to effectively and efficiently plan and design the (1) content, (2) structure and (3) process of the XPS program. Developing a large XPS in a multinational company typically takes about one year and includes the internal and external benchmarking of XPS-content by a cross-site-selected working group reporting to a steering committee of key stakeholders. The aim is to develop the XPS as far as possible before deployment to reduce confusion in the organisation. Also, each subsidiary must use some time in Phase 1 to figure out what the global XPS means for them-i.e. what is the local XPS, if different from the global XPS. This first phase is a pure establishment phase that has no direct operational effect.

Phase 2, 'Reengineering', is a necessary phase for many subsidiaries that still operate in accordance with the mass production logic or with a functional layout. It often includes a major change in the physical facility layout in a move towards flow production. The reengineering to Just-In-Time production requires the establishment of an intermediary storage of kitted subassemblies right next to the line, while the major material storage is moved away from the line. In addition to the layout change, there is a need to establish standards for work place management, often referred to as $5 \mathrm{~S}$, and standard operating procedures. Just-In-Time production is much more vulnerable to unplanned variability, and the need for standards is consequently much higher. In this phase, subsidiaries should take advantage of reengineering to establish a completely new and updated factory standard. This might include relative simple actions such as new flooring, white-painted walls, painted floor marking, atriums and green escapes, signs and symbols, improved artificial and natural lighting, energy-efficiency measures, and similar upgrading initiatives. Due to the transition to a leaner production system, the effect on productivity is often of an exponential nature. The physical layout change is a threshold for change that to some extent hinders reengineered companies from falling back to the old factory standard. Subsidiaries that have been through 
this phase before and already have a fairly good factory standard can of course quickly advance to Phase 3 as the XPS is introduced.

In Phase 3, 'Continuous Improvement', incremental improvements are introduced to the subsidiary on a regular basis. Standards should be updated based on a best-practice approach where the improvement suggestions are scientifically evaluated in a 'manufacturing laboratory'. This phase is difficult to sustain for a number of reasons. First, more than in the two first phases, this phase relies on the participation of all employees. Second, the organisational culture must foster improvement suggestions. Third, the XPS process and structure must be able to accommodate these suggestions. Fourth, the commitment from managers must be constant and uncompromised, even when managers shift positions. Finally, the system must allow for a high degree of ambiguity and uncertainty, because the XPS is a program that is shared between sites. This creates the need to examine the applicability of these standards across sites. The benefit from this phase is of an incremental, continuous and linear character, but if not constantly monitored and maintained, the organisation's growth is likely to plateau or move in a negative direction due to gravity towards a 'comfort zone' well below the performance frontier.

Phase 4, 'Process innovation', is a hard-won phase to reach and sustain. In this phase, the company is world class and improves by pushing the performance frontier. In order to do so, the company must succeed with process innovation, because imitating others only brings a company to the frontier and not beyond. The benefits in this phase are typically realised through a stepwise character where each innovation brings the subsidiary one step forward. The ability to innovate, spread and absorb the process innovation in the organisation relies on a widespread capacity for learning. Organisations that succeed are those that are able to capitalise on their cumulative brainpower available. Competence building in the preceding phases is hence a necessity.

\section{Discussion}

Four key characteristics of strategic programs were drawn from the program management literature. Strategic programs are proceeding, emergent, dynamic and people-oriented activities. This section discusses how these four characteristics fit with the XPS.

\section{The XPS is proceeding}

An XPS is intended as a never-ending strategic program of continuous improvement. XPSs are examples of what Pellegrinelli (1997) labels 'heartbeat programs'. 'Heartbeat programs are those which enable the regular improvement of existing systems, infrastructure or even business processes, via increments to functionality or occasionally an overhaul of the system or facility itself' (Pellegrinelli 1997: 143).

In practice, an XPS holds both infinite and finite characteristics: top management emphasises the strategic infinite purpose of continuous improvement, while managers at lower levels must also deal with the program as a series of finite improvement projects to climb the maturity ladder. One can argue that complete XPS implementation means that the program management is discontinued; it goes from being visible to being invisible. However, this will never happen in practice: different subsidiaries are at different levels, and the program itself must be continuously updated. Thus there will always be a need for some sort of XPS superstructure. This is very different from the more linear growth pattern of programs 
advocated by the MSP framework, which argues for closing the program when targets are met. The XPS is as a result a proceeding and infinite activity.

\section{The XPS is emergent}

The XPS is emergent for a number of reasons. First, the XPS lifecycle is emergent and different in each subsidiary. For any subsidiary at a given level, XPS program management must accommodate the subsidiary's individual need for XPS implementation. Second, it is emergent because the end goal is a 'moving target' as the performance frontier is pushed by competitors or the company itself. When this occurs, the content, structure and process of the XPS should be updated to meet the new world standards. Third, an XPS has the potential to start yielding results and positive payback from the beginning when deployed in phase 2 . Likewise, it can continue for years without resulting in any positive results. When implemented at large organisations, various subsidiaries will naturally experience different outcomes.

Finally, the XPS can also emerge in a negative direction; there is gravity in the model that constantly pulls improvements back to the original. Where there is change, there is resistance towards change. Positive results that are gained can quickly vanish if 'the program is ended'. To really implement the XPS means to change the underlying culture. The organisation has two means to block inertia from hindering XPS implementation; standards and culture building. Developing standards - supported by a strong organisational culture that maintains and adheres to the standards - is key for moving towards the performance frontier.

\section{The XPS is dynamic}

The XPS is dynamic because it includes a high degree of variability. Variability exists because subsidiaries are at different maturity stages at any given point of time. An XPS program must simultaneously deliver the same change capability in subsidiaries that naturally are at very different maturity stages. Therefore, the global XPS program must accommodate a multitude of requirements with regard to the content, structure and processes employed for different subsidiaries. The trick is to identify the level of maturity of the subsidiary, and then tailor the program management for its specific needs. This, however, is not easy because of the complex mix of contingencies at each subsidiary. Many multinational corporations that deploy XPSs have also developed assessment schemes that assess the maturity of subsidiaries. These can potentially be used to categorise subsidiaries into manageable entities.

\section{The XPS is people-oriented}

The real product of an XPS program is a capacity for change rather than a physical technology. This capacity for change cannot be implemented in full without a deeply rooted culture shift with which all employees must be on board. This is essentially about 'individual transitions' (Williams \& Parr 2004); even though the program aims for corporate-wide change, no change will take place if not individuals make their own transition from the old to the new state of affairs. The XPS aims to create a shared mind-set and to increase the openness to change among all employees in the organisation.

A result of this is that the program execution of an XPS must be part of the functional hierarchical organisation. Thus, the program management office or XPS support staff in a subsidiary should not become the leading force for its implementation. This is a major challenge for many program managers and also a key difference between XPS programs and technological implementation programs. More than for other programs, 'training and 
development opportunities for both leaders and employees will play a crucial role in building the necessary capabilities for program success' (Williams \& Parr 2004: 80).

\section{Proposing the XPS program management framework}

There is no doubt that the work done in developing the project-based program management frameworks - such as the MSP and EPM- over the past decade has helped program managers tremendously in understanding their work and finding proper focus, tools and methods for it. However, the project-based perspective is rightly criticised for being too rigid and uniform to fit a strategic program such as the XPS. The strategic perspective, on the other hand, is too vague and leaves XPS practitioners with little help other than advice to focus on competence building and to allow for different approaches. This section draws together the preceding literature review and the discussion, and proposes a program management framework for XPSs.

I agree with Thiry (2002), who suggests a joint competence-building and performanceoriented perspective in program management, in which value management is combined with project management to build an 'integrated learning-performance program management model'. The XPS program management framework proposed in this paper contributes towards this aim. The framework is developed by adapting the well-developed program management frameworks from the project perspective to the peculiarities of the XPS as a strategic program (Figure 4).

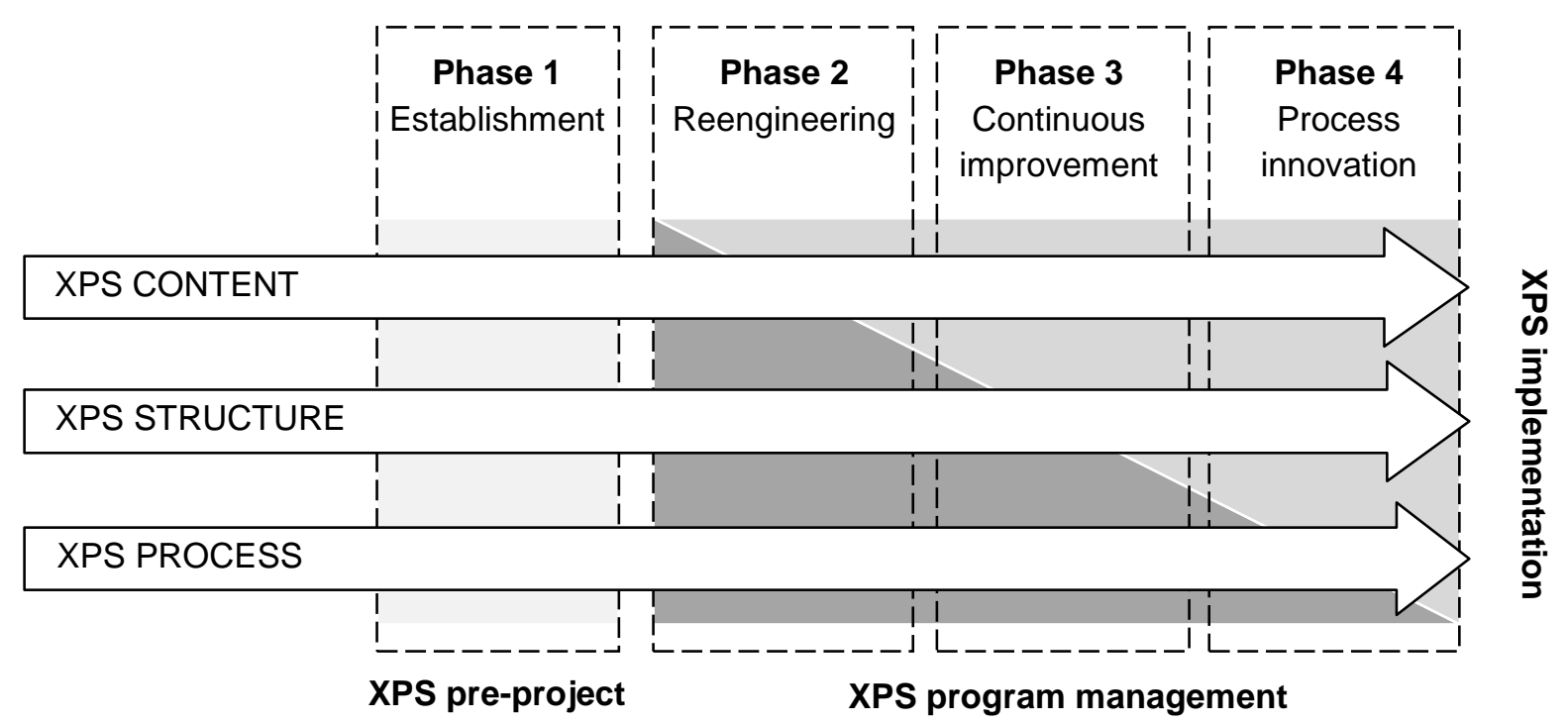

Figure 4: The XPS program management framework

The three XPS elements - 'content', 'structure' and 'process' - correspond to the tripartition shared in both the MSP and EPM frameworks. The four phases add manageability to a framework that is otherwise too holistic. Phase 1 is a project management phase needed to establish XPS content, structure, and process. Importantly, the program management of XPS is expected to decline as XPS implementation increases through implementation phases 2-4. This is illustrated by the grey triangle in Figure 4.

While it is suggested that the XPS journey should start as a series of projects, it risks running out of steam if it is run as a continuous series of projects led by the XPS program office or 
the XPS coordinator in subsidiaries. While good results can be achieved by a few dedicated employees in Phase 1 and Phase 2, Phase 3 and especially Phase 4 requires the participation of all employees in the organisation. If one follows the strategies outlined by program management frameworks such as the MSP (OGC 2011) and the EPM (Williams \& Parr 2004), one risks ending up with a bureaucracy that far exceeds the intention of the program. In advanced phases, the XPS must become part of everyday operations. The XPS must be 'infused' throughout the organisation over time. Ideally, employees will end up with two jobs; doing the job according to the standard and improving the standard.

\section{Guidelines for actions}

While there is a long list of activities in each of the four phases, some of these are essential (Table 2). The suggested activities are cumulative in the sense that all activities in the early phases must be sustained through the later phases.

Table 2: Essential activities for successful XPS program management

\begin{tabular}{|l|llll|}
\hline \multicolumn{1}{|c|}{ XPS phases } & $\begin{array}{l}\text { Phase 1 } \\
\text { Establishment }\end{array}$ & $\begin{array}{l}\text { Phase 2 } \\
\text { Reengineering }\end{array}$ & $\begin{array}{l}\text { Phase 3 } \\
\text { Continuous } \\
\text { improvement }\end{array}$ & $\begin{array}{l}\text { Phase 4 } \\
\text { Process } \\
\text { innovation }\end{array}$ \\
\hline $\begin{array}{l}\text { Content } \\
\text { Program change } \\
\text { content }\end{array}$ & $\begin{array}{l}\text { Identify and align } \\
\text { best practices to } \\
\text { strategy }\end{array}$ & $\begin{array}{l}\text { Reengineer plant } \\
\text { and get the basics } \\
\text { right (5S, SOP, JIT) }\end{array}$ & $\begin{array}{l}\text { Continuously } \\
\text { improve work } \\
\text { standards }\end{array}$ & $\begin{array}{l}\text { Benchmark others } \\
\text { and question the } \\
\text { XPS content }\end{array}$ \\
\hline $\begin{array}{l}\text { Structure } \\
\text { Program } \\
\text { architecture }\end{array}$ & $\begin{array}{l}\text { Establish XPS } \\
\text { program office }\end{array}$ & $\begin{array}{l}\text { Establish XPS } \\
\text { organisation and } \\
\text { roles }\end{array}$ & $\begin{array}{l}\text { Establish Kaizen } \\
\text { structures }\end{array}$ & $\begin{array}{l}\text { Diffuse all XPS } \\
\text { work into line } \\
\text { organisation }\end{array}$ \\
\hline $\begin{array}{l}\text { Process } \\
\text { Program delivery }\end{array}$ & $\begin{array}{l}\text { Secure top- } \\
\text { management } \\
\text { commitment }\end{array}$ & $\begin{array}{l}\text { Establish learning } \\
\text { and training } \\
\text { programs }\end{array}$ & $\begin{array}{l}\text { Do Gemba walks } \\
\text { and XPS audits to } \\
\text { sustain attention }\end{array}$ & $\begin{array}{l}\text { Achieve double- } \\
\text { loop organisational } \\
\text { learning }\end{array}$ \\
\hline
\end{tabular}

\section{Conclusions}

This conceptual paper has reviewed program management theory with the purpose of discussing its suitability and implications for the management of a particular type of strategic improvement program: the XPS. While the growing program management literature has provided practitioners with sound and useful frameworks for many types of mega-projects, it has largely failed to do the same for strategic programs. Strategic programs are proceeding, emergent, dynamic and people-oriented activities. The XPS provides a good example of a strategic program and is a widespread phenomenon in industry today.

The XPS program management framework proposed here is based on the process perspective that allows managers to focus attention on different phases of the program. A first project phase is needed to establish the program. Thereafter, by performing XPS program management, subsidiaries should be able to move through three phases: reengineering, continuous improvement, and finally process innovation. It is suggested that each phase requires a specific focus in the subsidiary, but also that the focus of each phase must be sustained beyond that phase. The XPS for each phase is determined by its three elements: content, structure and process.

In practice, it has proven extremely difficult for companies to move beyond the reengineering phase. Part of the reason for the high failure rate can be attributed to the lack of clear 
guidelines for program management. To meet this challenge, this paper has developed an XPS program management framework by bridging the project and strategic perspectives in the program management literature. The proposed XPS program management framework can help practitioners to focus their attention and resources on different phases of global XPS implementation.

\section{References}

Bateman, N. \& David, A. (2002) Process improvement programmes: A model for assessing sustainability. International Journal of Operations \& Production Management, 22, 515.

Clarke, C. (2005) Automotive production systems and standardisation: from Ford to the case of Mercedes-Benz, Heidelberg, Physica-Verlag.

Dombrowski, U., Schulze, S. \& Otano, I. C. (2009) Instandhaltungsmanagement als Gestaltungsfeld Ganzheitlicher Produktionssysteme. IN REICHEL, J., MÜLLER, G. \& MANDELARTZ, J. (Eds.) Betribliche Instandhaltung. Berlin Heidelberg, Springer.

Ferns, D. (1991) Developments in programme management. International Journal of Project Management, 9, 148-156.

Gray, R. J. (1997) Alternative approaches to programme management. International Journal of Project Management, 15, 5-9.

Honnef, H.-G., Hoffmeyer, W., Spanner-Ulmer, B., Springer, R., Ritter, J. \& Lentes, H.-P. (2000) Produktionssysteme im Vergleich. IN HOFMAN, A. (Ed.) Arbeitsorganisation in der Automobilindustrie - Stand und Ausblick. Köln, Wirtschaftsverlag Bachem.

Lycett, M., Rassau, A. \& Danson, J. (2004) Programme management: a critical review. International Journal of Project Management, 22, 289-299.

Macduffie, J. P. (2000) Internationale Entwicklungen in der Arbeitsorganisation der Automobilindustrie - Der Unterscheid zwischen den USA und Europa in der Einführung schlanker Produktionsverfahren. IN HOFMAN, A. (Ed.) Arbeitsorganisation in der Automobilindustrie - Stand und Ausblick. Köln, Wirtschaftsverlag Bachem.

Milosevic, D. Z., Martinelli, R. \& Waddell, J. M. (2007) Program Management for Improved Business Results, John Wiley \& Sons.

Netland, T. H. (2012) Exploring the phenomenon of company-specific Production Systems: One-best-way or own-best-way? International Journal of Production Research, DOI:10.1080/00207543.2012.676686.

Netland, T. H. \& Aspelund, A. (2013) Company-specific Production Systems and Competitive Advantage: A resource-based view on the Volvo Production System. International Journal of Operations \& Production Management, Forthcoming.

Ogc (2007) Managing successful programmes, United Kingdom, The Stationary Office, Office of Government Commerce

Ogc (2011) Managing Successful Programmes, Norwich, United Kingdom, The Stationary Office, Office of Government Commerce

Pellegrinelli, S. (1997) Programme management: organising project-based change. International Journal of Project Management, 15, 141-149.

Pellegrinelli, S. (2008) Thinking and acting as a reat programme manager, New York, Palgrave Macmillian. 
Pellegrinelli, S., Partington, D., Hemingway, C., Mohdzain, Z. \& Shah, M. (2007) The importance of context in programme management: An empirical review of programme practices. International Journal of Project Management, 25, 41-55.

Reiss, G. (1996) Programme management demystified: managing multiple projects successfully, London, Spon Press.

Schonberger, R. J. (2007) Japanese production management: An evolution - With mixed success. Journal of Operations Management, 25, 403-419.

Springer, M. L. (2001) Program management: a comprehensive overview of the discipline, West Lafayette, IN, Purdue University Press.

Thiry, M. (2002) Combining value and project management into an effective programme management model. International Journal of Project Management, 20, 221-227.

Vereecke, A., Pandalaere, E., Deschoolmeesterl, D. \& Stevens, M. (2003) A classification of development programmes and its consequences for programme management. International Journal of Operations \& Production Management, 23, 1279.

Westkämper, E., Hummel, V. \& Rönnecke, T. (2009) Ganzheitliche Produktionssysteme. IN WESTKÄMPER, E. \& ZAHN, E. (Eds.) Wandlungsfähige Produktionsunternehmen Das Stuttgarter Unternehmensmodell. Berlin Heidelberg, Springer.

Williams, D. \& Parr, T. (2004) Enterprise programme management: delivering value, Basingstoke, Hampshire, Palgrave Macmillan.

\footnotetext{
i The abbreviation XPS reflects the fact that a majority of such programs are named 'Company name' Production System. The term XPS also covers variants such as 'Company name' Operations System / Business System / Manufacturing System or other more unique labels.

ii The literature usually separates between projects, programs and portfolios: A project is a temporary organisation established for the purpose of delivering a defined output. Programs consist of a number of coordinated projects, and program portfolios consist of a number of coordinated programs. A key idea is that program management coordinates the projects so that the total outcome is greater than the sum of its individual projects, and portfolio management provides the same benefits to programs.

iii Examples of valuable project management techniques include: Breakdown structures (WBS, OBS, PBS, etc.), budgeting, project software systems, Gantt diagrams, Program Evaluation and Review Technique, business case modelling (net present value, return on investment, payback time, etc.), milestone charts, earned value analysis, resource histograms, cumulative cost curves, critical path analysis, risk log, change control procedures, decision tree analysis, cause and effect diagrams, fishbone diagrams, formal sign-off processes, project audits, project libraries, template libraries and debriefing, etc. Moreover, standardised project management methods such as PRINCE2 and the Project Management Institute's global standards for project management are also of great use.

iv The data collection method is explained in detail in the author's paper Netland, T. H. (2012) Exploring the phenomenon of company-specific Production Systems: One-best-way or own-best-way? International Journal of Production Research, DOI:10.1080/00207543.2012.676686..
}

\section{About the author:}

Torbjørn Netland is a PhD Candidate at the Norwegian University of Science and Technology, Trondheim, and a research scientist at SINTEF Technology and Society, Trondheim. He has been awarded a Fulbright Scholarship to visit McDonough School of Business, Georgetown University, Washington DC, for the academic year 2011/2012.

Email: torbjorn.netland@iot.ntnu.no 